\title{
Wheat streak mosaic virus Coat Protein Deletion Mutants Elicit More Severe Symptoms Than Wild-Type Virus in Multiple Cereal Hosts
}

\author{
Satyanarayana Tatineni, ${ }^{1,+}$ Christian Elowsky, ${ }^{2}$ and Robert A. Graybosch ${ }^{\mathbf{3}}$ \\ ${ }^{1}$ United States Department of Agriculture-Agricultural Research Service (USDA-ARS) and Department of Plant Pathology, \\ University of Nebraska-Lincoln; ${ }^{2}$ Department of Agronomy and Horticulture, University of Nebraska-Lincoln; and ${ }^{3}$ USDA-ARS \\ and Department of Agronomy and Horticulture, University of Nebraska-Lincoln, Lincoln, NE 68583, U.S.A.
}

Accepted 23 August 2017.

Previously, we reported that coat protein (CP) of Wheat streak mosaic virus (WSMV) (genus Tritimovirus, family Potyviridae) tolerates deletion of amino acids 36 to 84 for efficient systemic infection of wheat. In this study, we demonstrated that WSMV mutants with deletion of $\mathrm{CP}$ amino acids 58 to 84 but not of 36 to 57 induced severe chlorotic streaks and spots, followed by acute chlorosis in wheat, maize, barley, and rye compared with mild to moderate chlorotic streaks and mosaic symptoms by wild-type virus. Deletion of CP amino acids 58 to 84 from the WSMV genome accelerated cell-to-cell movement, with increased accumulation of genomic RNAs and CP, compared with the wildtype virus. Microscopic examination of wheat tissues infected by green fluorescent protein-tagged mutants revealed that infection by mutants lacking $\mathrm{CP}$ amino acids 58 to 84 caused degradation of chloroplasts, resulting in acute macroscopic chlorosis. The profile of CP-specific proteins was altered in wheat infected by mutants causing acute chlorosis, compared with mutants eliciting wildtype symptoms. All deletion mutants accumulated CP-specific major protein similarly to that in wild-type virus; however, mutants that elicit acute chlorosis failed to accumulate a 31-kDa minor protein compared with wild-type virus or mutants lacking amino acids 36 to 57 . Taken together, these data suggest that deletion of CP amino acids 58 to 84 from the WSMV genome enhanced accumulation of $\mathrm{CP}$ and genomic RNA, altered CPspecific protein profiles, and caused severe symptom phenotypes in multiple cereal hosts.

Due to their small genetic coding capacity, viruses rely on host genes for replication, movement, and disease development. Many successful interactions of viruses with their hosts cause disease symptoms, and most plant viruses gained prominence because of the diseases they cause on agronomically important crops worldwide (García and Pallás 2015; Hull 2014). Among virus-induced disease phenotypes, chlorosis is the most common symptom phenotype, followed by leaf-puckering and distortion, apical necrosis, and stunting. Viruses that elicit these symptoms in plants have potential to cause severe disease resulting in significant economic losses. Virus-induced leaf chlorosis can result from changes in cellular homeostasis that affects

${ }^{\dagger}$ Corresponding author: Satyanarayana Tatineni;
E-mail: satya.tatineni@ars.usda.gov

This article is in the public domain and not copyrightable. It may be freely reprinted with customary crediting of the source. The American Phytopathological Society, 2017 chloroplast development or maintenance. Chlorosis in developing leaves will result in a mosaic or mottled pattern with abnormal chloroplasts in light green and yellow leaf areas and normal chloroplasts in dark green areas. In contrast, chlorosis in fully developed leaves mostly initiates as yellow spots at the infection sites, followed by uniform discoloration spreading along with virus infection (Hull 2014).

Wheat streak mosaic virus (WSMV) is the most economically important virus in wheat (Triticum aestivum L.) in the Great Plains region of the United States (Brakke 1987; French and Stenger 2004). WSMV is the type species of the genus Tritimovirus of the family Potyviridae with a 9,384-nucleotide positive-sense RNA genome [excluding the poly(A) tail at the $3^{\prime}$ end] encapsidated in flexuous filamentous particles of 690 to $700 \mathrm{~nm} \times 11$ to $15 \mathrm{~nm}$ (Stenger et al. 1998). The genomic RNA contains a single large open reading frame that encodes a polyprotein of $350 \mathrm{kDa}$ and a P3N-PIPO protein of $32 \mathrm{kDa}$ within the polyprotein (Fig. 1). The polyprotein is cleaved into at least ten mature proteins by the three virus-encoded proteinases $\mathrm{P} 1$, HC-Pro (helper component proteinase), and NIa-Pro. WSMV is transmitted by the wheat curl mite (Aceria tosichella Keifer) (Slykhuis 1955), and both HC-Pro and coat protein (CP) have been implicated as viral determinants for mite transmission (Stenger et al. 2005a, 2006; S. Tatineni unpublished data). The genomic RNA is encapsidated by a single CP. However, purified virions isolated from wheat usually contain several serologically related proteins, typically a $45-\mathrm{kDa}$ major and a $31-\mathrm{kDa}$ minor $\mathrm{CP}$ (Brakke et al. 1990; Tatineni and French 2014). Accumulation of multiple CP-specific proteins in wheat was hypothesized to be due to proteolysis of the $45-\mathrm{kDa}$ major protein during leaf senescence (Brakke et al. 1990).

Composed of 349-amino acid residues, WSMV CP is substantially longer, compared with, for example, the 267-amino acid residue long CP of Potato virus $Y$, which is the type member of the genus Potyvirus (Robaglia et al. 1989; Stenger et al. 1998). The CP of WSMV tolerates deletion of amino acids 6 to 27 , 36 to 100 , or the C-terminal 17 amino acids for systemic infection of wheat (Tatineni et al. 2014). The amino-proximal amino acids 6 to 27 and 85 to 100 still are required for efficient virion assembly and cell-to-cell movement, and the carboxy-terminal 65 amino acids are dispensable for virion assembly but are required for cellto-cell movement. A WSMV CP mutant lacking amino acids 36 to 84 efficiently infects wheat with no noticeable effects on virion assembly and cell-to-cell or long-distance movement (Tatineni et al. 2014). WSMV CP contains three SGSGS (flexible linker) motifs at amino acid positions 36 to 40 (SGSGS-1), 43 to 47 (SGSGS-2), and 53 to 57 (SGSGS-3). While WSMV mutant 
lacking CP amino acids 36 to 84 efficiently infects wheat (Tatineni et al. 2014), the roles of SGSGS motifs and amino acids 58 to 84 in disease development are not known.

Wild-type WSMV induces chlorotic streaks, mosaic, and mottling on wheat leaves by 6 to 14 days postinoculation (dpi), under greenhouse conditions, and systemic symptoms generally become slightly milder with obvious stunting of plants by 21 dpi. However, WSMV does not induce extensive leaf chlorosis in wheat under greenhouse conditions (Stenger et al. 1998; Tatineni et al. 2010). Plant viruses encode proteins for pathogenicity, including suppressors of RNA silencing (Pruss et al. 1997; Voinnet et al. 2000). Similarly, WSMV P1 was reported as a suppressor of RNA silencing and a pathogenicity determinant (Young et al. 2012). The roles of additional WSMV proteins in symptom development are not known. Availability of a series of WSMV CP deletion mutants with efficient systemic infection in wheat will facilitate examination of one or more potentially multifunctional roles of $\mathrm{CP}$ in the wheat streak mosaic disease development.

In this study, the role of CP amino acids 36 to 84 in WSMV pathogenicity was investigated by introducing subsets of deletions within amino acids 36 to 57 (comprising individual or all SGSGS motifs) and 36 to 84 and examining symptom phenotypes of these deletion mutants in multiple cereal hosts. Deletion of CP amino acids 58 to 84 but not of 36 to 57 from the WSMV genome enhanced virus accumulation, altered CP-specific protein profiles, and caused acute leaf chlorosis in multiple cereal hosts, with concomitant degradation of chloroplasts.

\section{RESULTS}

WSMV CP amino acids 36 to 57 are dispensable for symptom induction.

The role of WSMV CP SGSGS motifs in symptom expression was examined by precisely deleting codons encoding for individual or all SGSGS motifs to obtain WSMV-CP $\Delta 36-40$ aa (SGSGS-1), WSMV-CP $\triangle 43-47$ aa (SGSGS-2), WSMV-CP $\triangle 53-$ 57aa (SGSGS-3), and WSMV-CP $\triangle 36-57$ aa (all three SGSGS motifs) (Fig. 1). WSMV mutants with deletion of individual or all
SGSGS motifs efficiently infected 84 to $100 \%$ of wheat seedlings by 7 to $9 \mathrm{dpi}$, similarly to that of wild-type virus (Fig. 1). Partially purified virions from wheat infected by SGSGS deletion mutants were examined by transmission electron microscopy and virus particles with no obvious morphological difference from those of the wild-type virus were found (Fig. 2B; data not shown). The presence of introduced deletions in the $\mathrm{CP}$ cistron was examined from 14-dpi systemically infected wheat leaves by reverse transcription-polymerase chain reaction (RT-PCR), using oligonucleotides XV1 (corresponding to nucleotides 8,096 to 8,121) and XC1 (complementary to nucleotides 9,373 to 9,348 ), and products of the expected size were obtained (Fig. 2C). Gel-eluted RT-PCR products comprising the complete CP cistron (nucleotides 8,189 to 9,238 ) were directly sequenced using oligonucleotides XV1 and XC1, and in all cases, it was found that mutants retained the introduced deletions and no second-site mutations within the $\mathrm{CP}$ cistron were observed.

Wheat seedlings infected with in vitro transcripts of WSMVCP $\Delta$ 36-40aa, WSMV-CP $\Delta 43-47 \mathrm{aa}$, WSMV-CP $\Delta 53-57 \mathrm{aa}$, or WSMV$\mathrm{CP} \triangle 36-57 \mathrm{aa}$ were examined for symptom development. All these mutants elicited mild chlorotic streaks, mosaic, and mottling symptoms at 14 and $21 \mathrm{dpi}$, similarly to those of the wild-type virus (Fig. 2A). These data indicate that deletion of SGSGS motifs from WSMV capsid protein, either individually or together, did not have a significant effect on symptom phenotype in wheat.

\section{Deletion of CP amino acids 58 to 84 from the WSMV genome elicited severe symptoms in wheat.}

Previously, we reported that CP amino acids 36 to 84 are dispensable for systemic infection of wheat, with no noticeable effects on virus cell-to-cell and long-distance movement (Tatineni et al. 2014). The above experiments revealed that $\mathrm{CP}$ amino acids 36 to 57 have no significant role on WSMV symptom induction in wheat. We next examined the role of $\mathrm{CP}$ amino acids 58 to 84 in symptom development by introducing deletions comprising amino acid codons 58 to 84 or 49 to 83 to obtain WSMV-CP $\Delta 58$ 84aa and WSMV-CP $\triangle 49-83$ aa, respectively (Fig. 1). In vitro transcripts of WSMV-CP $\Delta 58-84 \mathrm{aa}, \mathrm{WSMV-CP} \Delta 49-83 \mathrm{aa}$, and

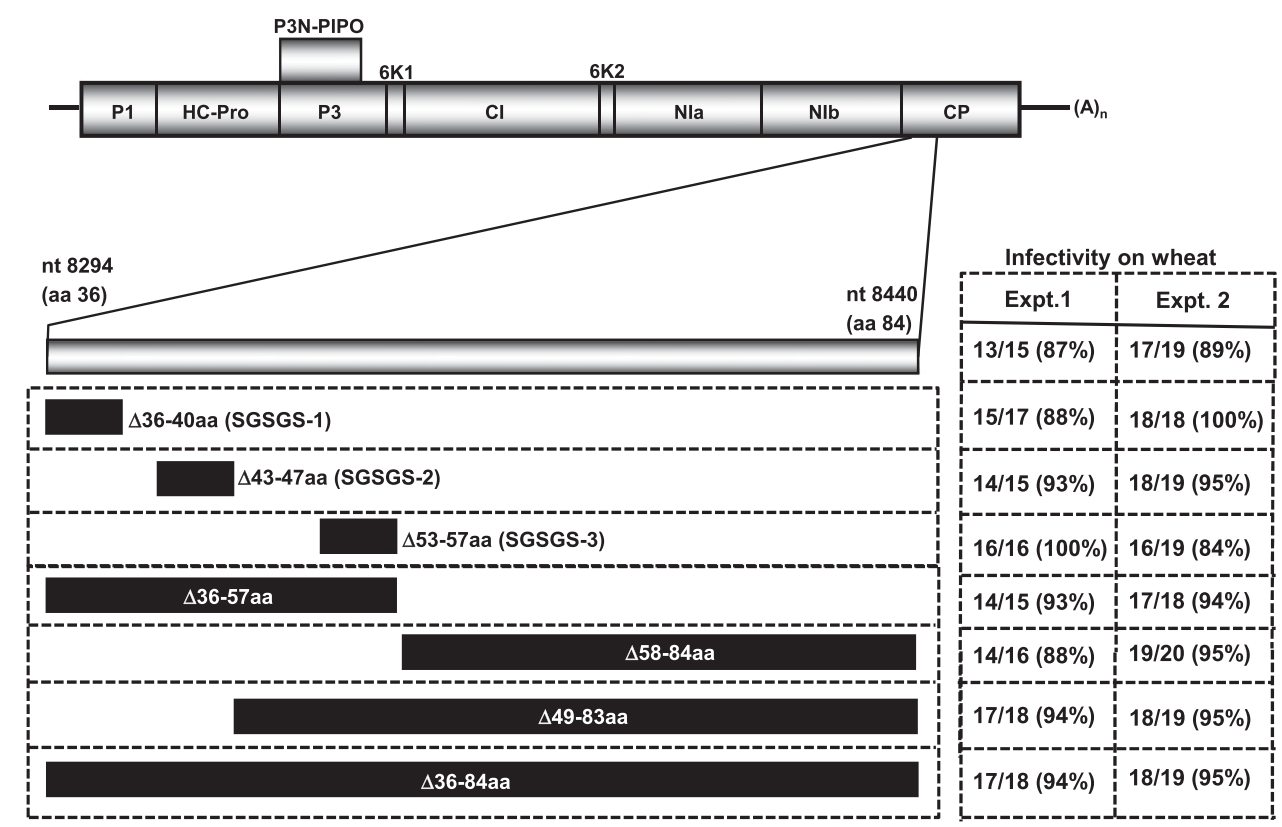

Fig. 1. Schematic diagram of Wheat streak mosaic virus (WSMV) genomic organization. The mature proteins from proteolytic cleavage of polyprotein are indicated inside the large open reading frame. The engineered deletions in the coat protein $(\mathrm{CP})$ are indicated with solid rectangles in an expanded view of amino acids 1 to 84 of the CP. SGSGS: Flexible linker amino acids present at positions 36 to 40,43 to 47 , and 53 to 57 in CP. Infectivity of wild-type virus and mutants with deletions in the $\mathrm{CP}$ cistron in wheat at 14 days postinoculation from two independent experiments is indicated next to the genetic organization of deletion mutants. 
WSMV-CP $\triangle 36-84$ aa (Tatineni et al. 2014) efficiently (88 to $95 \%$ ) infected wheat seedlings at 7 to 9 dpi (Fig. 1). Partially purified virions from WSMV-CP $\triangle 58-84$ aa- or WSMV-CP $\Delta 36$ 84aa-infected wheat at $14 \mathrm{dpi}$ were examined under a transmission electron microscope and virus particles with no obvious morphological difference from wild-type virus were found (Fig. 2B). RT-PCR amplification of the CP cistron from WSMVCPA58-84aa-, WSMV-CP $\Delta 49-83$ aa-, or WSMV-CP $\triangle 36-84 a a-$ infected wheat at 14 dpi obtained products of the expected size (Fig. 2C). Direct sequencing of gel-eluted RT-PCR products revealed that WSMV harbored the introduced deletions in the $\mathrm{CP}$ with no other unintended nucleotide changes.

Wheat infected by WSMV-CP $\Delta 58-84$ aa, WSMV-CP $\Delta 49$ 83aa, or WSMV-CP $\triangle 36-84$ aa elicited more severe symptoms compared with wild-type virus (Fig. 2A). At 7 to $9 \mathrm{dpi}$, these deletion mutants elicited chlorotic streaks and spots with mild leaf yellowing symptoms compared with only chlorotic streaks elicited by wild-type virus. At 14 and $21 \mathrm{dpi}$, WSMV-CP $\triangle 58$ 84aa, WSMV-CP $\triangle 49-83 \mathrm{aa}$, and WSMV-CP $\triangle 36-84 \mathrm{aa}$ elicited severe chlorotic streaks and spots in upper noninoculated leaves that caused severe yellowing compared with mild chlorotic streaks and mottling and mosaic symptoms elicited by wildtype virus (Fig. 2A). Wheat infected by these deletion mutants were stunted compared with wild-type virus-infected plants. These data indicate that infection by WSMV mutants lacking $\mathrm{CP}$ amino acids 58 to 84 elicited acute chlorosis in wheat.

\section{Severe symptom phenotype of CP deletion mutants is not a host-specific phenomenon.}

To determine whether increased symptom phenotype of $\mathrm{CP}$ deletion mutants in wheat is a host-specific phenomenon, seedlings of maize (Zea mays L.) inbred line SDp2, barley (Hordeum vulgare L.) cv. Metcalfe, and rye (Secale cereale L.) cv. Petkus were inoculated with the crude sap of wheat leaves infected with in vitro transcripts of deletion mutants. At 7 dpi, WSMV-CP $\triangle 58-$ 84aa, WSMV-CP $\triangle 49-83 \mathrm{aa}$, and WSMV-CP $\Delta 36-84$ aa elicited hypersensitive reaction-like chlorotic lesions on inoculated leaves of maize compared with no visible lesions by wild-type virus or mutants with deletions comprising individual or all SGSGS motifs (Fig. 3A; data not shown).
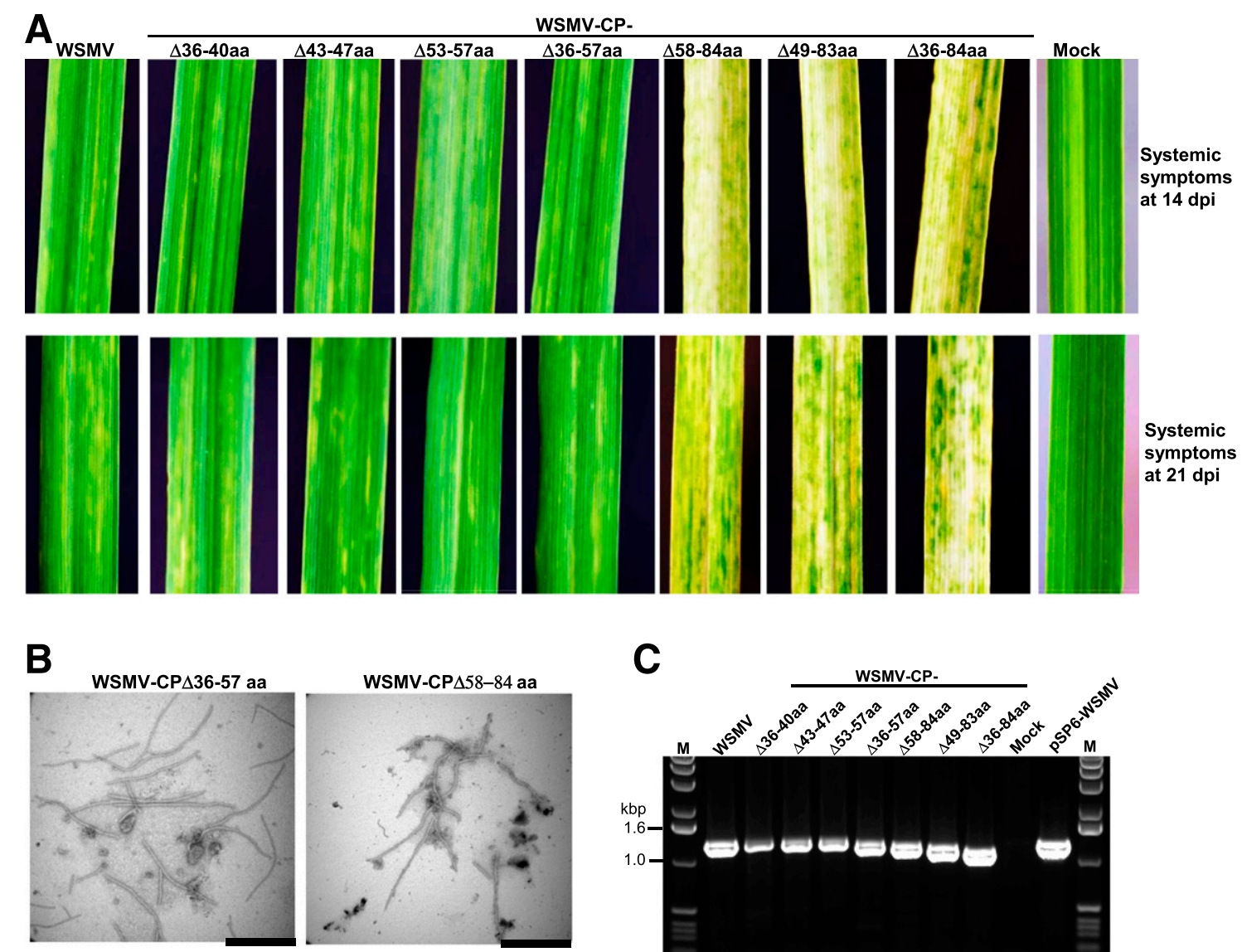

WSMV-CP $\triangle 36-84$ aa
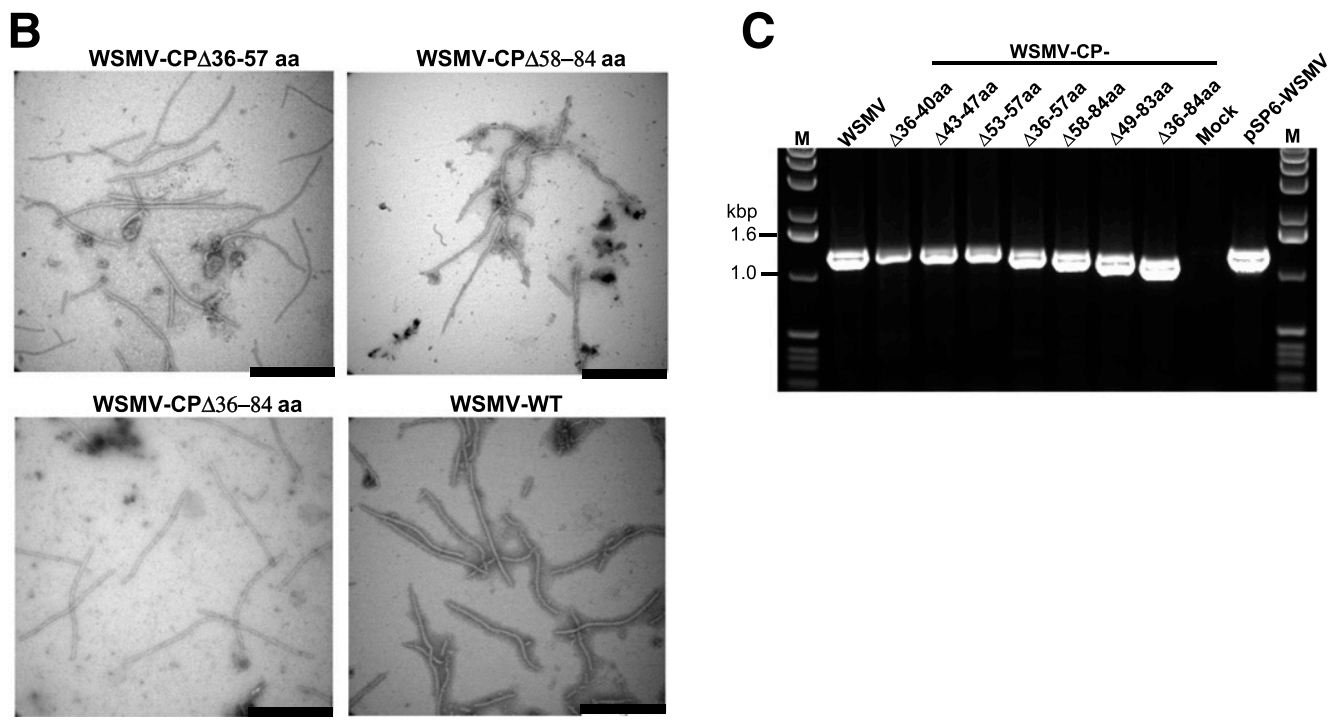

Fig. 2. Wheat streak mosaic virus (WSMV) with deletion of coat protein (CP) amino acids 58 to 84 elicited acute leaf chlorosis in wheat. A, Symptom phenotype of WSMV $\mathrm{CP}$ deletion mutants on wheat cv. Tomahawk at 14 and 21 days postinoculation (dpi). The deleted amino acids from CP of WSMV are indicated above the leaf pictures. B, Transmission electron micrographs of wild type and CP deletion mutants from systemically infected wheat leaves. Bars = 500 nm. C, Reverse transcription-polymerase chain reaction (RT-PCR) amplification of the CP cistron from wheat systemically infected with wild type and CP deletion mutants at 14 dpi. The RT-PCR products were gel electrophoresed through $1.0 \%$ agarose, and positions of 1.0- and 1.6-kbp bands of 1.0-kbp DNA ladder (lanes M) are indicated. Mock = buffer inoculated wheat. 
At 14 dpi, WSMV-CP $\triangle 36-40 a a$, WSMV-CP $\triangle 43-47 a a$, WSMV$\mathrm{CP} \triangle 53-57 \mathrm{aa}$, and WSMV-CP $\triangle 36-57$ aa elicited mild chlorotic streaks and stripes and mosaic symptoms in maize, barley, and rye, similarly to wild-type virus. In contrast, WSMV-CP $\Delta 58-84$ aa, WSMV-CP $\triangle 49-83 \mathrm{aa}$, and WSMV-CP $\triangle 36-84$ aa elicited moderate to severe chlorotic streaks and stripes. By 21 dpi, WSMV mutants lacking CP amino acids 58 to 84 elicited large chlorotic streaks and stripes resulting in severe leaf yellowing on maize, barley, and rye compared with mild chlorotic streaks elicited by wild-type virus and the various SGSGS mutants (Fig. 3B, C, and $\mathrm{D}$; data not shown). These data suggest that the severe symptom phenotype of $\mathrm{CP}$ mutants lacking amino acids 58 to 84 in wheat is not host-specific.

\section{Deletion of CP amino acids 58 to 84 enhanced accumulation of $\mathrm{CP}$ and genomic RNA.}

Severe symptoms induced by CP deletion mutants could be due to enhanced accumulation of mutant viruses. This possibility was examined by inoculating wheat seedlings at the single-leaf stage with crude sap from wheat leaves infected with in vitro transcripts of deletion mutants. Total proteins and RNAs were isolated from systemically infected wheat leaves to examine the accumulation of CP and the number of viral genomic RNAs, respectively.

Western blot analyses of total proteins with polyclonal antibodies against WSMV capsid protein indicated that WSMV mutants with deletions comprising individual or all SGSGS motifs accumulated $\mathrm{CP}$ at 0.8 - to 1.1 -fold of wild-type virus at 9 and $14 \mathrm{dpi}$ (Fig. 4A). These data revealed that $\mathrm{CP}$ of mutants with deletions encompassing amino acids 36 to 57 accumulated approximately similarly to that of wild-type virus. In contrast, CP from wheat plants infected by WSMV-CP $\triangle 58$ 84aa, WSMV-CP $\Delta 49-83 \mathrm{aa}$, or WSMV-CP $\triangle 36-84$ aa accumulated at 2.2- to 2.3- and 1.7- to 1.9-fold of wild-type virus at 9 and $14 \mathrm{dpi}$, respectively (Fig. 4A). These data revealed that infection by WSMV mutants comprising a deletion of $\mathrm{CP}$ amino acids 58 to 84 caused a significant increase in accumulation of CP.

The number of genomic RNA copies of CP deletion mutants in wheat at 14 dpi was quantified with real-time RT-PCR. The genomic RNA copies of deletion mutants comprising individual or all SGSGS motifs encompassing amino acids 36 to 57 accumulated at slightly increased, though not significantly greater, levels at 1.1- to 1.2-fold of wild-type virus (Fig. 4B). In contrast, genomic RNA copies of WSMV-CP $\triangle 58-84 a a$, WSMV-CP $\triangle 49-83 \mathrm{aa}$, and WSMV-CP $\Delta 36-84 \mathrm{aa}$ accumulated at statistically significantly increased levels at 1.5- to 2.2-fold of wild-type virus (Fig. 4B). These data indicate that deletion of $\mathrm{CP}$ amino acids 58 to 84 from the WSMV genome significantly increased accumulation of $\mathrm{CP}$ and genomic RNAs compared with wild-type virus.
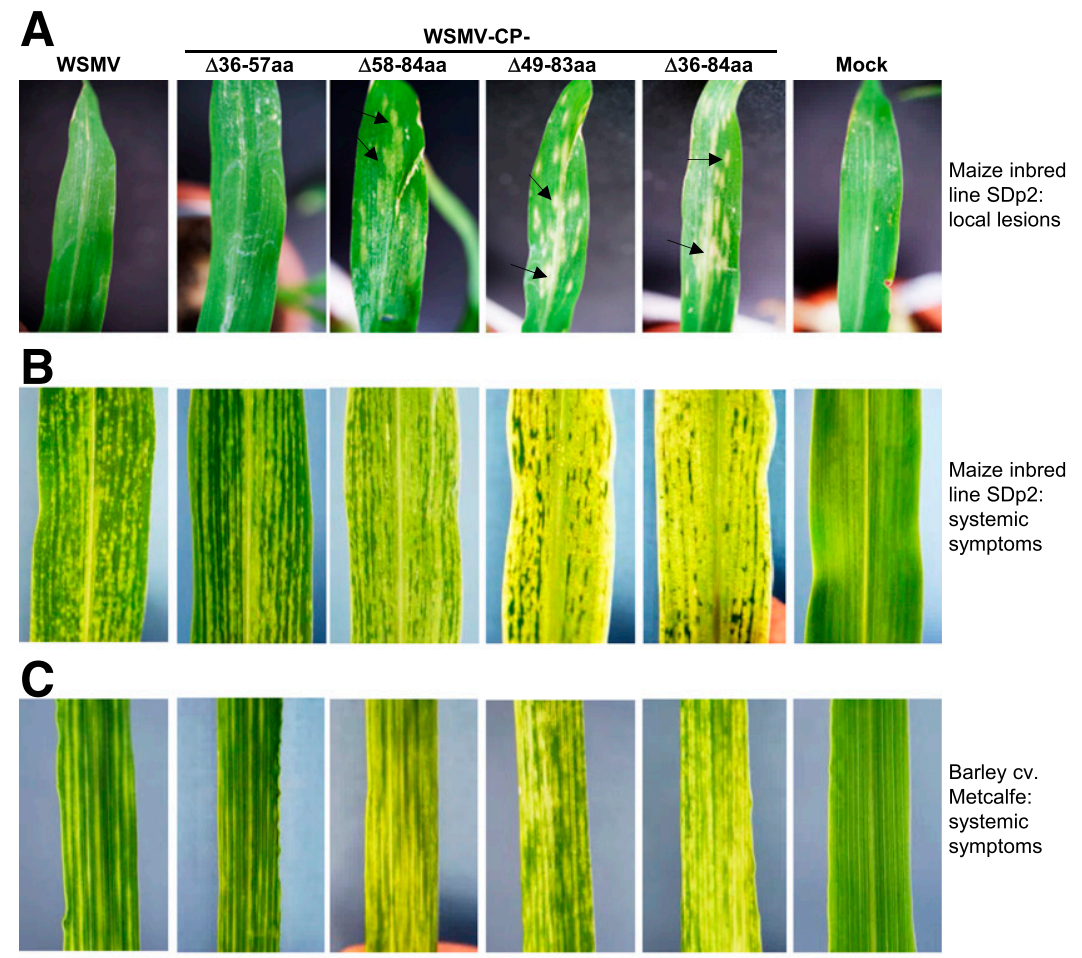

Barley cv.

Metcalfe:

systemic
symptoms

D
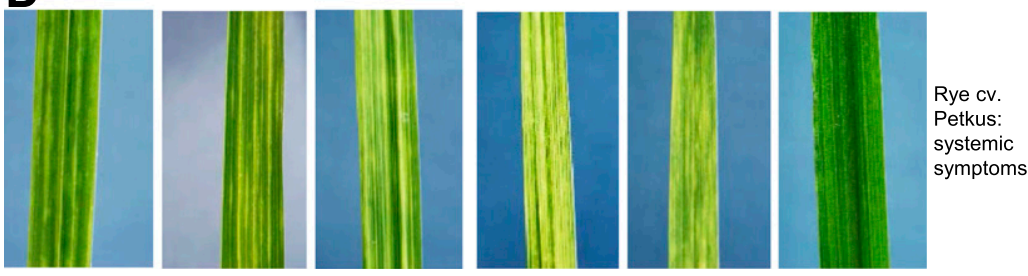

Fig. 3. Wheat streak mosaic virus (WSMV) with deletions comprising amino acids 58 to 84 in the coat protein (CP) elicited severe symptoms in multiple cereal hosts. Maize, barley, and rye inoculated with the crude sap at a 1:20 dilution from wheat leaves infected with in vitro transcripts. A, Local lesions on maize inbred line SDp2 at 7 days postinoculation (dpi); B to D, Systemic symptoms of wild-type virus and CP deletion mutants on maize inbred line SDp2 (B), barley cv. Metcalfe (C), and rye cv. Petkus (D), at 21 dpi. Note that WSMV-bearing deletions comprising CP amino acids 58 to 84 elicited severe symptoms in maize, barley, and rye. 
CP mutants eliciting severe symptoms failed to accumulate the 31-kDa CP-specific minor protein in wheat.

Previously, it has been reported that two CP-specific proteins, with estimated sizes of approximately 45 (major) and $31 \mathrm{kDa}$ (minor), were detected in partially purified virions from WSMV-infected wheat (Brakke et al. 1990; Tatineni and French 2014). Additionally, a 29-kDa protein was sometimes detected at much reduced levels. These minor CP-specific proteins were attributed to in vivo proteolytic
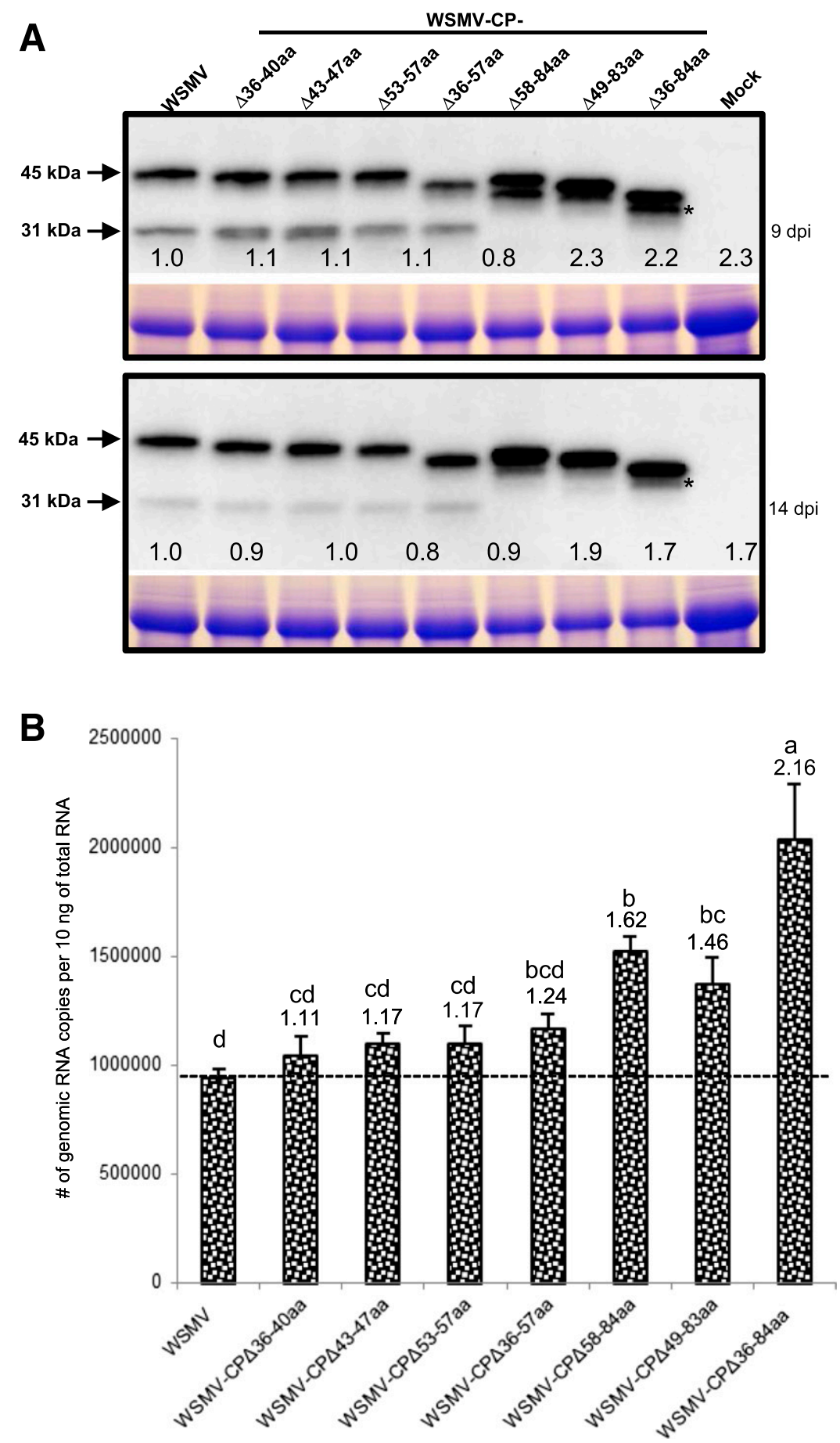

Fig. 4. Deletions in the coat protein (CP) of Wheat streak mosaic virus (WSMV) enhanced accumulation of CP and genomic RNA copies. A, Western blot analysis of total proteins of wheat infected with wild-type virus or CP deletion mutants at 9 and 14 days postinoculation (dpi). The blots were probed with polyclonal antisera produced against WSMV purified virions. Accumulation of major CP-specific protein (top band) reacted with WSMV polyclonal antisera was quantified, and numbers at the bottom of each lane are the fold accumulation of the respective major protein over wild-type virus. The position of 45- and 31-kDa CP-specific proteins are indicated with arrows. Note the absence of 31-kDa CP-specific protein in wheat-infected with WSMV lacking CP amino acids 58 to 84. Asterisks indicate accumulation of a different CP-specific minor protein in mutants lacking amino acids 58 to 84. Coomassie-stained sodium dodecyl sulfate-polyacrylamide electrophoresis gels shown below the Western blots are the amount of large subunit of wheat RuBisCo protein as a loading control for the amount of total protein loaded per well. B, Quantification of WSMV genomic RNA copies of wild-type virus or mutants with deletions in the CP cistron from systemically infected wheat at 14 dpi. Total RNA extracted from triplicate samples from each mutant virus-infected wheat leaves. The histograms represent the number of WSMV genomic RNA copies accumulated per $10 \mathrm{ng}$ of total RNAs \pm standard error. Numbers presented above the histograms are fold change in genomic RNAs accumulation in CP deletion-mutants infected wheat over wild-type virus. The dotted line indicates the number of genomic RNAs accumulation by wild-type virus. Different letters above the histograms indicate significant differences between mutants at $P<0.05$, while means with the same letter were not significantly different. 
degradation of 45-kDa CP during leaf senescence (Brakke et al. 1990).

Analysis of CP-specific proteins in deletion mutant-infected wheat, by Western blots with polyclonal antibodies against WSMV capsid protein, revealed that the major $\mathrm{CP}$ and minor 31-kDa proteins accumulated in WSMV-CP $\triangle 36-40 \mathrm{aa}-$, WSMVCP $\Delta 43-47 a a-$, WSMV-CP $\Delta 53-57$ aa-, or WSMV-CP $\Delta 36-57$ aainfected wheat at 9 and $14 \mathrm{dpi}$, similarly to that of wild-type virus (Fig. 4A). These data suggest that mutants with deletions encompassing amino acids 36 to 57 accumulated a major protein and a $31-\mathrm{kDa}$ minor protein, as reported previously (Brakke et al. 1990; Tatineni and French 2014). Conspicuously, in WSMV-CP $\Delta 58-84 a a-$, WSMV-CP $\Delta 49-83$ aa-, or WSMV-CP $\Delta 36$ $84 \mathrm{aa}$-infected wheat, the major $\mathrm{CP}$-specific protein but not the 31-kDa minor protein accumulated at 9 and 14 dpi (Fig. 4A). However, a different minor protein was detected just below the major CP-specific protein at 9 dpi but at significantly reduced levels at $14 \mathrm{dpi}$ (Fig. 4A). The 31-kDa minor protein was also absent in 7-dpi wheat leaves infected with in vitro transcripts of $\mathrm{CP}$ deletion mutants lacking amino acids 58 to 84 (data not shown). These data suggest that the $31-\mathrm{kDa} \mathrm{CP}$-specific minor protein did not accumulate in wheat infected by severe symptom-inducing mutants lacking $\mathrm{CP}$ amino acids 58 to 84 .

\section{Deletion of CP amino acids 58 to 84 facilitated increased cell-to-cell movement of WSMV.}

The possibility of enhanced accumulation of deletion mutants might lead to more rapid cell-to-cell movement was examined using mutants eliciting severe symptom phenotypes. Deletion of amino acids 53 to 57,36 to 57 , or 58 to 84 were introduced in the CP cistron in WSMV-GFP-6K1/CI(7aa) (Fig. 4A) (Tatineni et al. 2011), to obtain WSMV-GFP-CP $\Delta 53-57 \mathrm{aa}$, WSMV-GFP-CP $\triangle 36-57 \mathrm{aa}$, and WSMV-GFP-CP $\Delta 58-84 \mathrm{aa}$, respectively. WSMV-GFP-CP $\triangle 36-84$ aa was described previously

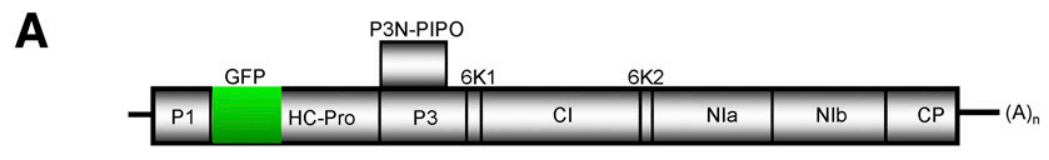

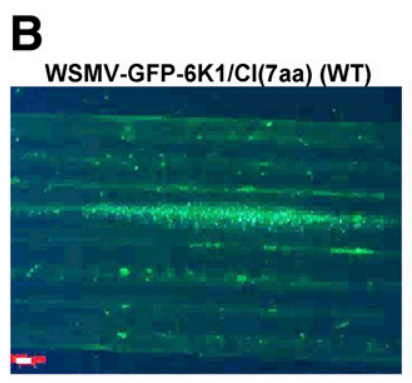
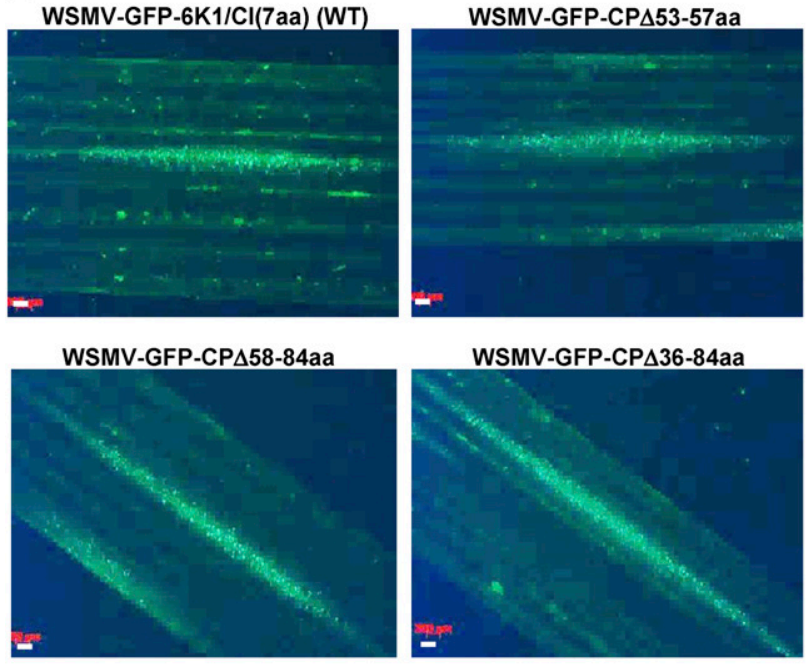

C

\begin{tabular}{|l|l|l|}
\hline \multirow{2}{*}{\multicolumn{1}{|c|}{ Mutant }} & \multicolumn{2}{c|}{ Foci size $\left(\mathrm{mm}^{2} \pm\right.$ SE) } \\
\cline { 2 - 3 } & \multicolumn{1}{|c|}{ Exp. 1 } & Exp. 2 \\
\hline WSMV-GFP-6K1/CI(7aa) (WT) & $2.31 \pm 0.44 \mathrm{c}$ & $1.30 \pm 0.24 \mathrm{c}$ \\
\hline WSMV-GFP-CP $\Delta 53-57 \mathrm{aa}$ & $2.80 \pm 0.63 \mathrm{~b}$ & $1.31 \pm 0.31 \mathrm{c}$ \\
\hline WSMV-GFP-CP $\Delta 36-57 \mathrm{aa}$ & $2.85 \pm 0.50 \mathrm{~b}$ & $1.36 \pm 0.43 \mathrm{bc}$ \\
\hline WSMV-GFP-CP $\Delta 58-84 \mathrm{aa}$ & $3.31 \pm 0.64 \mathrm{a}$ & $1.47 \pm 0.33 \mathrm{ab}$ \\
\hline WSMV-GFP-CP $\triangle 36-84 \mathrm{aa}$ & $2.74 \pm 043 \mathrm{~b}$ & $1.56 \pm 0.33 \mathrm{a}$ \\
\hline Mock & 0 & 0 \\
\hline
\end{tabular}

In vitro transcripts-inoculated wheat seedlings were incubated in a greenhouse (Exp. 1) and in a growth chamber (Exp. 2).

The size of foci estimated at 4 dpi (Exp. 1) and 3 dpi (Exp. 2). SE: Standard error. Foci sizes with different letters indicate significant differences between mutants at $\mathrm{P}<0.05$, while means with the same letter were not significant.

Fig. 5. Cell-to-cell movement of Wheat streak mosaic virus (WSMV) coat protein (CP) deletion mutants in wheat. A, Schematic diagram of the genomic organization of green fluorescent protein (GFP)-tagged WSMV. Sequence encoding for GFP (in green) with a 7-amino acid cleavage peptide located between the 6K1 and CI cistrons at its C terminus was inserted between the P1 and HC-Pro cistrons of WSMV (Tatineni et al. 2011). B, The fluorescent foci developed by wild-type virus or mutants harboring deletions in the $\mathrm{CP}$ on inoculated wheat leaves at 4 days postinoculation. Bars $=200 \mu \mathrm{m}$. $\mathbf{C}$, The size of fluorescent foci elicited by wild-type and CP deletion mutants on in vitro transcript-inoculated wheat leaves. Note that WSMV with deletions comprising CP amino acids 58 to 84 elicited statistically significantly large foci compared with wild-type virus. 
(Tatineni et al. 2014). In vitro transcripts of green fluorescent protein (GFP)-tagged deletion mutants were inoculated onto wheat seedlings and were observed for the development of local foci at 3 or $4 \mathrm{dpi}$, under a Zeiss Stereo Discovery V12 fluorescence dissecting microscope (Carl Zeiss MicroImaging, Inc., New York). At 4 dpi (experiment 1), all mutants elicited statistically significantly larger foci than wild-type virus (Fig. 5B and C), while at 3 dpi (experiment 2), only WSMV-GFP-CP $\triangle 58-84$ aa and WSMVGFP-CP $\triangle 36-84 a a$ elicited significantly larger foci than wild type (Fig. 5B and C). These data suggest that deletion of $\mathrm{CP}$ amino acids 58 to 84 from the WSMV genome accelerated the cell-to-cell movement of mutant viruses in wheat, as compared with wild-type virus.

\section{Acute chlorosis in wheat by CP deletion mutants is due to degradation of chloroplasts.}

In contrast to systemic mild chlorotic streaks and mosaic symptoms elicited by wild-type virus and mutants with the deletion of individual or all SGSGS motifs, systemic infections by mutants lacking CP amino acids 58 to 84 caused acute chlorosis (Fig. 2A). Progression of acute chlorosis in wheat by $\mathrm{CP}$ deletion mutants was examined using GFP-tagged mutant viruses. Previously, we reported that GFP formed as dense aggregate-like structures in wheat infected by WSMV-GFP6K1/CI(7aa) (WSMV-GFP) (Tatineni et al. 2011), and deletions were introduced into the CP cistron of WSMV-GFP. The integrity of chloroplasts in wheat leaves systemically infected by GFP-tagged WSMV or deletion mutants was examined at 9, 14, and 21 dpi under a confocal microscope (Fig. 6).

At 9 dpi, GFP was detected in wheat infected by wild-type virus and all deletion mutants and appeared to have no significant effect on chloroplast structure (Fig. 6, top panel). In the confocal images, GFP is pseudo-colored green, chloroplast autofluorescence is red, and the signal between the two, where damaged chloroplasts shift, is pseudo-colored blue. Thus, intact and healthy chloroplasts are red and damaged ones are blue. In wheat infected by deletion mutants causing acute chlorosis,
GFP accumulated similarly or slightly more, compared with wild-type virus or WSMV-GFP-CP $\triangle 36-57$ aa (Fig. 6). At 14 and $21 \mathrm{dpi}$, wheat infected by WSMV-GFP (wild-type) and WSMVGFP-CP $\triangle 36-57$ aa exhibited intact grana with no significant degradation of chloroplasts (Fig. 6, middle and bottom panels). In contrast, wheat infected by WSMV-GFP-CP $\Delta 58-84$ aa or WSMV-GFP-CP $\Delta 36-84$ aa dramatically affected the grana, as most of the infected leaf areas appear blue (Fig. 6, middle and bottom panels). Moreover, most of the chloroplasts in leaves with acute chlorosis have no distinct shape. Additionally, at 14 and $21 \mathrm{dpi}$, wheat leaves with acute chlorosis have several pink-colored chloroplasts (Fig. 6, middle and bottom panels), suggesting that these chloroplasts are most likely in the process of degradation. Taken together, these data suggest that wheat infection by CP deletion mutants lacking amino acids 58 to 84 might have caused degradation of chloroplasts.

\section{DISCUSSION}

Previously, it was reported that WSMV CP amino acids 36 to 84 were dispensable for efficient systemic infection of wheat (Tatineni et al. 2014). In the present study, the role of these amino acids on WSMV symptom phenotype was examined by introducing subsets of deletions. Amino acids 36 to 57 were found to have no role on symptom expression phenotype. Notably, however, mutants with deletion of amino acids 58 to 84 caused acute chlorosis in multiple cereal hosts, increased virus accumulation, and a shift in $\mathrm{CP}$-specific proteins.

Multifunctional viral CPs possess several independent or overlapping domains that likely function in a tightly coordinated manner with virtually every amino acid playing a critical role in the virus infection cycle (Callaway et al. 2001). In contrast, WSMV CP amino acids 36 to 84 are dispensable for efficient systemic infection of wheat (Tatineni et al. 2014). WSMV CP has three SGSGS (flexible linker) motifs, between amino acid positions 36 and 57, with no known function.
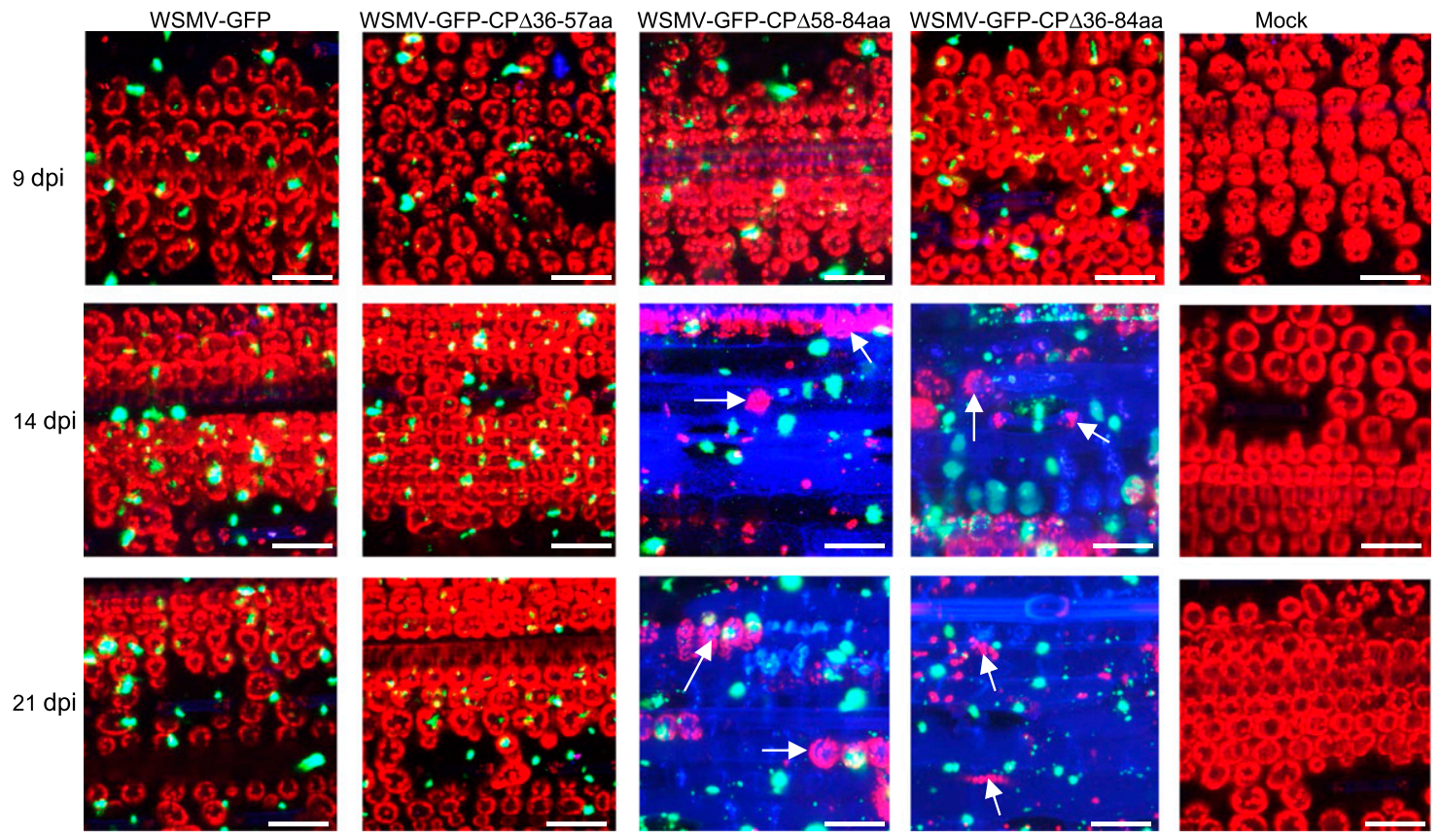

Fig. 6. Acute chlorosis by Wheat streak mosaic virus (WSMV) coat protein (CP) deletion mutants is due to degradation of chloroplasts. Wheat seedlings inoculated at the single-leaf stage with in vitro transcripts of WSMV-GFP (wild-type) or CP deletion mutants were observed under a confocal microscope at 9, 14, and 21 days postinoculation (dpi). The upper fully expanded wheat leaves were observed for GFP expression (pseudo-colored green) and the health of chloroplasts. Healthy chloroplasts have intense autofluorescence, pseudo-colored red, while degraded chloroplasts emit in a different channel (blue). Arrows indicate pink-colored chloroplasts (red and blue colocalized) that are in the process of degradation. Note the absence of round-shaped red-colored chloroplasts in mutants lacking amino acids 58 to 84 or 36 to 84 at 14 and 21 dpi, indicating degradation of chloroplasts. Mock $=$ buffer-inoculated wheat. Bars $=50 \mu$ m. 
Deletion of these motifs, either individually or jointly, elicited symptoms similarly to those of the wild-type virus, indicating that amino acids 36 to 57 are not involved in symptom phenotype. In contrast, deletion of amino acids 58 to 84 elicited severe chlorotic streaks and spots, followed by acute yellowing of leaves. It is puzzling why deletion of CP amino acids 58 to 84 induced substantially more severe symptoms compared with wild-type virus.

In general, deletion of nonessential plant viral genes causes attenuated symptoms in their hosts (Petty et al. 1990; Prokhnevsky et al. 2002; Tatineni et al. 2008). Previously, Stenger et al. (2005b) reported that WSMV mutants with deletions in HC-Pro or with heterologous HC-Pro cistrons also caused milder symptoms on wheat compared with wild-type virus. However, results presented in this study differ from the above examples, as none of those deletions were in multifunctional CP. Though CP is dispensable for WSMV replication (Tatineni et al. 2014), due to the multifunctional nature of viral CPs, it is surprising that WSMV mutants with deletion of amino acids 58 to 84 elicited more severe symptoms than wild-type virus in several cereal hosts. Recently, these amino acids were also found to be involved in wheat curl mite transmission of WSMV, while amino acids 36 to 57 were dispensable (S. Tatineni unpublished data). Thus, CP amino acids 36 to 57 are superfluous for symptom phenotype and wheat curl mite transmission, while amino acids 58 to 84 are involved in suppression of symptom phenotype and mite transmission. It is not clear why the WSMV genome retains the sequence that seems to be involved in suppression of symptoms. It is possible that $\mathrm{CP}$ amino acids 58 to 84 indirectly facilitate longevity of WSMV by extending host plant life by suppressing virulence. Incidentally, wheat curl mites feed only on green tissue. Extending the longevity of the host plant extends the time frame during which mites may acquire the virus for transmission.

The acute chlorosis symptom phenotype of $\mathrm{CP}$ deletion mutants is not host-specific. Our data indicated that WSMV $\mathrm{CP}$ deletion mutants that caused severe symptoms in wheat also elicited similar symptoms in maize inbred line SDp2, barley, and rye compared with the wild-type virus. Additionally, these mutants accumulated increased levels of genomic RNAs and CP in wheat and facilitated accelerated cell-to-cell movement, suggesting that deletion of amino acids 58 to 84 enhanced WSMV accumulation. Why do deletions in the CP cistron contribute to increased accumulation of WSMV? Perhaps smaller genome size due to introduced deletions might have contributed to increased virus accumulation and thus elicited severe symptoms in multiple cereal hosts. However, a 22-amino acid deletion comprising residues 36 to 57 in the $\mathrm{CP}$ did not elicit a severe symptom phenotype. It is unlikely that a 26 -amino acid deletion of residues 58 to 84 reduces the size of genomic RNA significantly, compared with a 22 -amino acid deletion comprising amino acids 36 to 57 . Thus, smaller genome size of deletion mutants is not the likely reason for increased virus accumulation and enhanced symptom phenotype observed in this study. It is possible that deletions might have changed the secondary structure of $\mathrm{CP}$, which might have facilitated increased interactions with host proteins. The increased CP-host protein interactions might have contributed to enhanced virus accumulation and severe symptom phenotype. Alternatively, these amino acids may encode a suppressor of virulence and deletion of these amino acids from WSMV genome might have caused increased symptom phenotype. Additionally, it appears that acute chlorosis symptoms of $\mathrm{CP}$ deletion mutants are not solely due to elevated virus titers, because WSMV expressing the suppressor of RNA silencing (P1) of Triticum mosaic virus (Tatineni et al. 2012) accumulated at higher levels but failed to elicit a severe symptom phenotype in wheat (S. Tatineni unpublished).
In contrast to major (approximately $45 \mathrm{kDa}$ ) and minor (31 kDa) CP-specific proteins accumulation in wheat infected by wild-type virus or SGSGS deletion mutants, the severe symptom-inducing $\mathrm{CP}$ deletion mutants accumulated only the major protein but not the $31-\mathrm{kDa}$ minor protein. However, severe symptom-inducing $\mathrm{CP}$ deletion mutants lacking amino acids 58 to 84 accumulated a different minor protein just below the major protein at $9 \mathrm{dpi}$ but at significantly reduced levels at $14 \mathrm{dpi}$. It is possible that deletion of CP amino acids 58 to 84 might have affected a cryptic cleavage site in $\mathrm{CP}$ that would have resulted in a $31-\mathrm{kDa}$ minor protein. However, this does not explain for the presence of a different minor protein at $9 \mathrm{dpi}$ but almost no such protein at $14 \mathrm{dpi}$.

Previously, the presence of lower molecular weight CPspecific proteins from WSMV-infected wheat was hypothesized as the result of accelerated leaf senescence due to virus infection (Brakke et al. 1990). However, mutants that elicit acute chlorosis (severe senescence) did not accumulate the 31$\mathrm{kDa} \mathrm{CP}$-specific minor protein, indicating that additional $\mathrm{CP}$ specific proteins are not solely the result of leaf senescence. These data suggest the intriguing possibility that the presence of the $31-\mathrm{kDa} \mathrm{CP}$-specific minor protein protects chloroplasts from degradation in WSMV-infected wheat. However, further investigation into the relationship between $31-\mathrm{kDa} \mathrm{CP}$-specific protein pathogenicity and chloroplast degradation is warranted.

Acute chlorosis was observed in wheat infected by CP deletion mutants at 14 and $21 \mathrm{dpi}$ but not at 9 dpi. Additionally, several chloroplasts that are in the process of degradation were also observed with acute chlorosis. Collectively, these data suggest that acute chlorosis in wheat infected by WSMV CP deletion mutants is most likely due to degradation of chloroplasts. Mutations in the CP gene of Tobacco mosaic virus (TMV) also elicited acute chlorosis in tobacco (Dawson et al. 1988; Lindbeck et al. 1992). However, WSMV mutants differ from those of TMV in that WSMV CP deletion mutants formed infectious virions (Tatineni et al. 2014), while TMV CP mutants did not (Dawson et al. 1988; Lindbeck et al. 1991). It has been postulated that virion assembly-deficient CP of TMV mutants forms aggregate-like structures, and these aggregates might have contributed to acute chlorosis (Lindbeck et al. 1991, 1992). In contrast to TMV, virion formation is required for cellto-cell and long-distance movement of WSMV, and severe symptom-inducing CP deletion mutants form virions similarly to wild-type virus (Tatineni et al. 2014).

Recently, we found that CP amino acids 58 to 84 are also required for WSMV transmission by wheat curl mites (S. Tatineni unpublished data), and it is interesting that $\mathrm{CP}$ amino acids required for vector transmission are also involved in suppression of virulence. This further supports the possibility of involvement of these amino acids in extending the longevity of WSMV. Moreover, these CP deletion mutants most likely cannot survive in nature because these mutants cannot be transferred horizontally by wheat curl mites. This study provides compelling evidence that deletion of $\mathrm{CP}$ amino acids 58 to 84 increases WSMV pathogenicity and symptom severity, and the availability of a series of viable $\mathrm{CP}$ deletion mutants will greatly facilitate understanding of the complexity of virusplant interactions of a monocot-infecting virus.

\section{MATERIALS AND METHODS}

\section{WSMV CP deletion mutants.}

pSP6-WSMV-S81, an infectious cDNA clone of WSMV isolate Sidney 81 (Choi et al. 1999) was the basis for all deletion mutants generated in this study. In-frame deletion of nucleotides encoding for amino acids 36 to 40,43 to 47,53 to 57,36 to 57,58 to 84 , and 49 to 83 in the CP cistron were created in 
pSP6-WSMV-S81, using overlap extension PCR (Ho et al. 1989) as described by Tatineni et al. (2014), to obtain pSP6-WSMVCP $\Delta 36-40 a a$, pSP6-WSMV-CP $\Delta$ 43-47aa, pSP6-WSMV-CP $\Delta 53-$ 57aa, pSP6-WSMV-CP $\Delta 36-57 \mathrm{aa}, \mathrm{pSP6}-\mathrm{WSMV-CP} \Delta 58-84 \mathrm{aa}$, and pSP6-WSMV-CP $\Delta 49-83 \mathrm{aa}$, respectively. The overlap extension PCR products were ligated into pSP6-WSMV-S81 between the BstEII (at nucleotide 6,319) and SpeI (at the $3^{\prime}$ end) restriction endonuclease sites. The overlap extension PCR products containing deletion of nucleotides encoding for amino acids 53 to 57,36 to 57 , or 58 to 84 were also ligated into pSP6WSMV-GFP-6K1/CI(7aa) (Tatineni et al. 2011) to obtain pSP6WSMV-GFP-CPA53-57aa, pSP6-WSMV-GFP-CP $\Delta 36-57 \mathrm{aa}$, and pSP6-WSMV-GFP-CP $\triangle 58-84 a a$, respectively. pSP6-WSMV$\mathrm{CP} \triangle 36-84 \mathrm{aa}$ and pSP6-WSMV-GFP-CP $\triangle 36-84$ aa were previously described by Tatineni et al. (2014).

Ligation reactions followed by transformation into Escherichia coli JM109 cells (Promega, Madison, WI, U.S.A.) were performed as described by Sambrook and Russell (2001). Plasmid DNAs were prepared from 40-ml cultures grown overnight, using a Bio-Rad plasmid midiprep kit (Bio-Rad, Hercules, CA, U.S.A.). The presence of engineered deletions in plasmid DNAs was confirmed by nucleotide sequencing. Initially, three independent clones per mutants were examined in phenotypic studies, followed by one clone per mutant in three to four independent experiments.

\section{Plant inoculations.}

Freshly prepared in vitro transcripts in a $40-\mu l$ reaction from $1.0 \mu \mathrm{g}$ of linearized plasmid DNA were directly inoculated onto wheat cv. Tomahawk seedlings at the single-leaf stage, as described by Tatineni et al. (2011). Briefly, freshly prepared in vitro transcripts were mixed with an equal volume of $2 \%$ sodium pyrophosphate, $\mathrm{pH}$ 9.0, containing approximately $1.0 \%$ celite, and were inoculated onto 15 to 20 wheat seedlings. Inoculated wheat seedlings were incubated in a greenhouse at 20 to $27^{\circ} \mathrm{C}$, with $14 \mathrm{~h}$ of daylight or artificial light for symptom development. To ensure efficient infection, crude sap from wheat leaves infected with in vitro transcripts of $\mathrm{CP}$ deletion mutants was used to inoculate maize inbred line SDp2, barley cv. Metcalfe, and rye cv. Petkus, at a 1:20 dilution in $20 \mathrm{mM}$ sodium phosphate buffer, $\mathrm{pH}$ 7.0. Inoculated plants were incubated in a greenhouse for symptom development.

\section{RT-PCR assay.}

Total RNA extracted from upper fully expanded symptomatic wheat leaves at $14 \mathrm{dpi}$ (McNeil et al. 1996) was used as a template for first-strand cDNA synthesis in a $10-\mu$ l volume with random primers (Promega), as described by Tatineni et al. (2010). One microliter of the first-strand cDNA was used for PCR in a $25-\mu 1$ reaction with primers XV1 and $\mathrm{XC1}$, flanking either side of the CP cistron, using a PCR program described by Tatineni et al. (2014). The RT-PCR products were analyzed on $1.0 \%$ agarose gels in Tris-acetate-EDTA buffer.

\section{Transmission electron microscopy assay.}

Wheat leaves infected with in vitro transcripts of WSMVS81, WSMV-CP $\triangle 36-57 \mathrm{aa}$, WSMV-CP $\triangle 58-84$ aa, or WSMV$\mathrm{CP} \triangle 36-84 \mathrm{aa}$ at $14 \mathrm{dpi}$ were used for partial purification of virions as described by Tatineni et al. (2014). Partially purified virions were used to prepare 400-mesh carbon-coated grids and were observed under a Hitachi H-7500 transmission electron microscope.

\section{Examining cell-to-cell movement of $\mathrm{CP}$ deletion mutants.}

Wheat seedlings were inoculated at the single-leaf stage with in vitro transcripts of WSMV-GFP-6K1/CI(7aa) (wild-type), WSMV-GFP-CP $\Delta 53-57$ aa, WSMV-GFP-CP $\Delta 36-57 a a$, WSMV-GFP-
CP $\triangle 58-84 \mathrm{aa}$, or WSMV-GFP-CP $\triangle 36-84 \mathrm{aa}$, as described above. Cellto-cell movement of GFP-tagged wild-type virus and CP deletion mutants was monitored by examining the formation of local foci on inoculated leaves (at the single-leaf stage) under Zeiss Stereo Discovery V12 fluorescence microscope, using a narrow-band GFP filter set 38 (400 to $450 \mathrm{~nm}$ excitation and 450 to $490 \mathrm{~nm}$ emission). The GFP fluorescence pictures were captured using an AuxioCam MRc5 camera attached to the fluorescent microscope. The size of foci was measured for approximately 20 individual foci, as described by Tatineni et al. (2014).

\section{Confocal microscopy of GFP-tagged \\ WSMV CP deletion mutants.}

Wheat leaves infected with WSMV-GFP or CP deletion mutants at 9, 14, and 21 dpi were imaged with a Nikon A1 laser scanning confocal microscope on a Nikon 90i upright fluorescence microscope (Nikon, Tokyo) controlled with NIS-Elements. The excitation of GFP was $488 \mathrm{~nm}$ and the emission was detected between 500 to $550 \mathrm{~nm}$ and pseudo-colored green. Intact chloroplast autofluorescence excitation and emission were $640 \mathrm{~nm}$ and 650 to $720 \mathrm{~nm}$, respectively, and were pseudo-colored red. Autofluorescence from degraded chloroplasts was excited with $561 \mathrm{~nm}$ and was detected from 575 to $625 \mathrm{~nm}$ and pseudo-colored blue. Images were taken as $\mathrm{Z}$-series with a $60 \times$ objective and maximum intensity projections were produced for comparisons.

\section{Western-blot assay.}

Wheat seedlings at the single-leaf stage were inoculated with the crude sap of wheat leaves infected with in vitro transcripts at 1:20 dilution, and inoculated plants were incubated in a greenhouse. Total proteins from $400 \mathrm{mg}$ of tissue were extracted as described by Tatineni et al. (2011). Ten microliters of total proteins were subjected to sodium dodecyl sulfate-polyacrylamide gel electrophoresis on 4 to $20 \%$ gels (Invitrogen, Carlsbad, CA, U.S.A.), followed by immunoblot analyses, using WSMV polyclonal antiserum, as described by Tatineni et al. (2014). The intensities of protein bands were quantified with the Molecular Imager ChemiDoc XRS+ system with Image Lab Software (Bio-Rad).

\section{Quantitative (q)RT-PCR assay.}

Total RNA was extracted from the same wheat leaves used for total protein with TriPure reagent (Roche, Indianapolis, IN, U.S.A.) as described by Tatineni et al. (2010). Total RNA was extracted from $200 \mathrm{mg}$ of infected leaf tissue, in triplicates, from each CP mutant. One microgram of total RNA was used to prepare the first-strand cDNA in a $10-\mu l$ volume, using random primers. The cDNAs were diluted to $1: 10$ and $1 \mu \mathrm{l}$ of diluted cDNAs were used for real-time PCR, using WSMV CP-specific primers and probe, as described by Tatineni et al. (2010).

\section{Statistical analyses.}

SAS and Excel programs were used for statistical computations of means and standard deviations for the following variables: genomic RNA copy number, as determined by qRT-PCR, and foci size. Analysis of variance and Duncan's multiple range test (Steel and Torrie 1980) were used to determine statistical differences in sample means.

\section{ACKNOWLEDGMENTS}

We thank R. French for critical reading of the manuscript; and J. Alexander and J. Horrell for excellent technical assistance. This project was supported, in part, by funds provided by the United States Department of Agriculture (USDA) National Institute of Food and Agriculture grant number 2013-68004-20358. USDA is an equal opportunity provider and employer. Mention of trade names or commercial products in this publication is solely for the purpose of providing specific information and does not imply recommendation or endorsement by the USDA. 


\section{LITERATURE CITED}

Brakke, M. K. 1987. Virus disease in wheat. Pages 585-603 in: Wheat and Wheat Improvement, 2nd ed., E. G. Heyne, ed. American Society of Agronomy, Crop Science Society of America, Soil Science Society of America, Madison, WI, U.S.A

Brakke, M. K., Skopp, R. N., and Lane, L. C. 1990. Degradation of Wheat streak mosaic virus capsid protein during leaf senescence. Phytopathology 80:1401-1405.

Callaway, A., Giesman-Cookmeyer, D., Gillock, E. T., Sit, T. L., and Lommel, S. A. 2001. The multifunctional capsid proteins of plant RNA viruses. Annu. Rev. Phytopathol. 39:419-460.

Choi, I. R., French, R., Hein, G. L., and Stenger, D. C. 1999. Fully biologically active in vitro transcripts of the eriophyid mite-transmitted wheat streak mosaic tritimovirus. Phytopathology 89:1182-1185.

Dawson, W. O., Bubrick, P., and Grantham, G. L. 1988. Modifications of the Tobacco mosaic virus coat protein gene affecting replication, movement, and symptomatology. Phytopathology 78:783-789.

French, R., and Stenger, D. C. 2004. Wheat streak mosaic virus. Pages 602-604 in: Viruses and Virus Diseases of Poaceae. H. Lapierre, and P. Signoret, eds. INRA Editions, Paris.

García, J. A., and Pallás, V. 2015. Viral factors involved in plant pathogenesis. Curr. Opin. Virol. 11:21-30.

Ho, S. N., Hunt, H. D., Horton, R. M., Pullen, J. K., and Pease, L. R. 1989. Site-directed mutagenesis by overlap extension using the polymerase chain reaction. Gene 77:51-59.

Hull, R. 2014. Plant Virology, 5th ed. Academic Press, New York.

Lindbeck, A. G. C., Dawson, W. O., and Thomson, W. W. 1991. Coat protein-related polypeptides from in vitro Tobacco mosaic virus coat protein mutants do not accumulate in the chloroplasts of directly inoculated leaves. Mol. Plant-Microbe Interact. 4:89-94.

Lindbeck, A. G. C., Lewandowski, D. J., Culver, J. N., Thomson, W. W., and Dawson, W. O. 1992. Mutant coat protein of Tobacco mosaic virus induces acute chlorosis in expanded and developing tobacco leaves. Mol. Plant-Microbe Interact. 5:235-241.

McNeil, J. E., French, R., Hein, G. L., Baenziger, P. S., and Eskridge, K. M. 1996. Characterization of genetic variability among natural populations of wheat streak mosaic virus. Phytopathology 86:1222-1227.

Petty, I. T., French, R., Jones, R. W., and Jackson, A. O. 1990. Identification of Barley stripe mosaic virus genes involved in viral RNA replication and systemic movement. EMBO J. 9:3453-3457.

Prokhnevsky, A. I., Peremyslov, V. V., Napuli, A. J., and Dolja, V. V. 2002. Interaction between long-distance transport factor and Hsp70-related movement protein of Beet yellows virus. J. Virol. 76:11003-11011.

Pruss, G., Ge, X., Shi, X. M., Carrington, J. C., and Bowman Vance, V. 1997. Plant viral synergism: The potyviral genome encodes a broadrange pathogenicity enhancer that transactivates replication of heterologous viruses. Plant Cell 9:859-868.

Robaglia, C., Durand-Tardif, M., Tronchet, M., Boudazin, G., AstierManifacier, S., and Casse-Delbart, F. 1989. Nucleotide sequence of Potato virus Y (N strain) genomic RNA. J. Gen. Virol. 70:935-947.
Sambrook, J., and Russell, D. W. 2001:Page 2344 in: Molecular cloning: A laboratory manual, 3rd Ed. Cold Spring Harbor Laboratory Press, Cold Spring Harbor, NY, U.S.A.

Slykhuis, J. T. 1955. Aceria tulipae Keifer (Acarina: Eriophyidae) in relation to spread of wheat streak mosaic virus. Phytopathology 45: 116-128.

Steel, R. G. D., and Torrie, J. H. 1980. Principles and Procedures of Statistics. A Biometrical Approach, 2nd ed. McGraw-Hill, New York.

Stenger, D. C., French, R., and Gildow, F. E. 2005b. Complete deletion of Wheat streak mosaic virus HC-Pro: A null mutant is viable for systemic infection. J. Virol. 79:12077-12080.

Stenger, D. C., Hall, J. S., Choi, I.-R., and French, R. 1998. Phylogenetic relationships within the family potyviridae: Wheat streak mosaic virus and brome streak mosaic virus are not members of the genus rymovirus. Phytopathology 88:782-787.

Stenger, D. C., Hein, G. L., and French, R. 2006. Nested deletion analysis of Wheat streak mosaic virus HC-Pro: Mapping of domains affecting polyprotein processing and eriophyid mite transmission. Virology 350:465-474.

Stenger, D. C., Hein, G. L., Gildow, F. E., Horken, K. M., and French, R. 2005a. Plant virus HC-Pro is a determinant of eriophyid mite transmission. J. Virol. 79:9054-9061.

Tatineni, S., and French, R. 2014. The C-terminus of Wheat streak mosaic virus coat protein is involved in differential infection of wheat and maize through host-specific long-distance transport. Mol. Plant-Microbe Interact. 27:150-162.

Tatineni, S., Graybosch, R. A., Hein, G. L., Wegulo, S. N., and French, R. 2010. Wheat cultivar-specific disease synergism and alteration of virus accumulation during co-infection with Wheat streak mosaic virus and Triticum mosaic virus. Phytopathology 100:230-238.

Tatineni, S., Kovacs, F., and French, R. 2014. Wheat streak mosaic virus infects systemically despite extensive coat protein deletions: Identification of virion assembly and cell-to-cell movement determinants. J. Virol. 88:1366-1380.

Tatineni, S., McMechan, A. J., Hein, G. L., and French, R. 2011. Efficient and stable expression of GFP through Wheat streak mosaic virus-based vectors in cereal hosts using a range of cleavage sites: Formation of dense fluorescent aggregates for sensitive virus tracking. Virology 410 : 268-281.

Tatineni, S., Qu, F., Li, R., Morris, T. J., and French, R. 2012. Triticum mosaic poacevirus enlists $\mathrm{P} 1$ rather than HC-Pro to suppress RNA silencing-mediated host defense. Virology 433:104-115.

Tatineni, S., Robertson, C. J., Garnsey, S. M., Bar-Joseph, M., Gowda, S., and Dawson, W. O. 2008. Three genes of Citrus tristeza virus are dispensable for infection and movement throughout some varieties of citrus trees. Virology 376:297-307.

Voinnet, O., Lederer, C., and Baulcombe, D. C. 2000. A viral movement protein prevents spread of the gene silencing signal in Nicotiana benthamiana. Cell 103:157-167.

Young, B. A., Stenger, D. C., Qu, F., Morris, T. J., Tatineni, S., and French, R. 2012. Tritimovirus P1 functions as a suppressor of RNA silencing and an enhancer of disease symptoms. Virus Res. 163:672-677. 